Khalilov F.Ya.

DOI: 10.25108/2304-1730-1749.iolr.2020.62.165-172

UDC 343.1

\title{
The right to defend in person or through legal assistance: case law of the European Court of Human Rights
}

\begin{abstract}
Article 6 of the European Convention for the Protection of Human Rights and Fundamental Freedoms guarantees every criminal prosecuted person the right to a fair trial. The right to a fair trial is a set of procedural rights, each of which has its own content and is an integral part of the right to a fair trial. In this context, ensuring the right of a criminally prosecuted person to defend himself personally or by means of his own counsel, or if he does not have the means to pay for the services of a defence counsel, to use the services of a defence counsel assigned to him free of charge when the interests of justice so require is also an integral part of the fairness of the proceedings.

As an integral part of the comprehensive law provided for in article 6 of the Convention and manifested in various aspects, the extent and quality of the right to participate in the defence counsel has a direct impact on the fairness of the proceedings. Although the case law of the European Court of Justice does not consider the participation of counsel in the trial as an absolute right, it is assessed as an additional guarantee of due process.

The participation of counsel in criminal proceedings in the context of the right to a fair trial was examined by the author through an analysis and systematization of the case law of the European Court of Human Rights.
\end{abstract}

Keywords: criminal trial; lawyer; fairness of trial; minimum rights, case-law practice; analysis.

\section{References}

1. Brusnitsyin L.V. Ogranichenie prava na svidaniya zaschitnika s podzaschitnyim v natsional'nom i mezhdunarodnom prave [Restriction of the right of defence counsel to visit the defendant in national and international law]. Gosudarstvo i pravo - State and Law, 2002, no. 11, pp. 105-109.

2. Harris D., O'Boyle M., Warbrick. Law of the European Convention on Human Rights. 2016. 1432 p. (Russ. ed. Harris, O Boyli, Uorbik. Pravo Evropeyskoy konventsii po pravam cheloveka: trans. By Vlasihin V.A. and others). Moscow, Razvitie pravovyikh sistem Publ., 2016, 1432 p.

3. Suleymanov J.I., Ismailova S.R., Radzhabova T.F., Teymurov A.A. Prava cheloveka i ugolovnyi protsess. Rukovodstvo po spravedlivomu sudoproizvodstvu [Human rights and criminal proceedings. Fair Trial Manual.]. Baku, Sada Publ., 2019, 417 p.

4. Aleksandr Zaichenko v. Russia, 28.06.2010, (Application no. 39660/02).

5. Alvarez Sanchez v. Spain, 23.10.2001, (Application no. 50720/99).

6. Artico v. Italy, 13.05.1980, 3 E.H.R.R. 1.

Khalilov Fardin Yashar oglu - PhD in Law, Chief Researcher of Academy of Justice of the Ministry of Justice of Azerbaijan Republic. E-mail: ph_d@mail.ru 
7. Biondo v. Italy, 05.05.1983, (Application no. 8821/79).

8. Campbell and Fell v. United Kingdom, 28.06.1984, 7 E.H.R.R. 165.

9. Can v. Austria, 30.09.1985, (Application no. 9300/81).

10.Castravet v. Moldova, 13.06.2007, (Application no. 23393/05).

11.Correia de Matos v. Portugal, 15.11.2001, (Application no. 48188/99).

12.Croissant v. Germany, 25.09.1992, 16 E.H.H.R. 135.

13.Czekalla v. Portugal, 10.10.2002, (Application no. 38830/97).

14.Dayanan v. Turkey, 13.01.2010, (Application no. 7377/03).

15.Foucher v. France, 18.03.1997, (Application no. 22209/93).

16. Goddi v. Italy, 09.04.1984, 6 E.H.R.R. 457.

17. Güveç v. Turkey, 20.01.2009, (Application no. 70337/01).

18. Imbrioscia v. Switzerland, 24.10.1993, 17 E.H.R.R. 441.

19. John Murray v. United Kingdom, 08.02.1996, 22 E.H.R.R. 29.

20. Kamasinski v. Austria, 19.12.1989, 19 E.H.R.R. 36.

21. Kempers v. Austria, 27.02.1997, (Application no. 21842/93).

22. Khodorkovskiy and Lebedev v. Russia, 25.10.2013, (Application nos. 11082/06 and $13772 / 05)$.

23. Köplinger v. Austria, 29.03.1966, (Application no. 1850/63).

24. Lagerblom v. Sweden, 14.01.2003, (Application no. 26891/95).

25. M v. United Kingdom, (1984) 36 D.R. 155.

26. McComb v. United Kingdom, (1968), 50 DR 81.

27. Meftah and Others v. France, 26.07.2002, (Application no. 32911/96).

28. Ocalan v. Turkey, 12.05.2005, 41 E.H.R.R. 985.

29. Pakelli v. Germany, 25.04.1983 (Application no. 8398/78).

30. Panovits v. Cyprus, 11.12.2008, (Application no. 4268/04).

31. Perks and others v. United Kingdom, 12.10.1999 (Application nos. 25277/94, 25279/94, 25280/94, 25282/94, 25285/94, 28048/95, 28192/95, 28456/95).

32. Pham Hoang v. France, 29.08.1992, 16 E.H.R.R. 53.

33. Pietilainen v. Finland, 22.09.2009, (Application no. 13566/06).

34. Pishchalnikov v. Russia, 24.12.2009, (Application no. 7025/04).

35. Poitrimol v. France, 23.11.1993, 18 E.H.R.R. 130.

36. Quaranta v. Switzerland, 24.05. 1991, (Application no. 12744/87).

37. Timergaliyev v. Russia, 14.10.2008, (Application no. 40631/02).

38. Salduz v. Turkey, 27.11.2008, (Application no. 36391/02).

39. Stanford v. United Kingdom, 23.02.1994, (Application no. 16757/90).

40. Şaman v. Turkey, 05.07.2011, (Application no. 35292/05).

41. Yaremenko v. Ukraine, 12.09.2008, (Application no. 32092/02).

42. Yurttas v. Turkey, 27.05.2004, (Application nos. 25143/94 and 27098/95).

43. Zagaria v. Italy, 27.11.2007, (Application no. 58295/00). 
DOI: 10.25108/2304-1730-1749.iolr.2020.62.165-172

УДК 343.1

\section{Право защищать себя лично или посредством выбранного защитника: прецедентное право Европейского Суда по правам человека}

Аннотация: Статья 6 Европейской Конвенции о защите прав человека и основных свобод гарантирует каждому уголовно преследуемому лицу право на справедливое судебное разбирательство. Право на справедливое судебное разбирательство представляет собой комплекс процессуальных прав, каждое из которых имеет свое собственное содержание и является неотьемлемой частью права на справедливое судебное разбирательство. В этом контексте, обеспечение права уголовно преследуемого лица защищать себя лично или посредством выбранного им самим защитника либо при недостатке у него средств для оплаты услуг защитника, пользоваться услугами назначенного ему защитника бесплатно, когда того требуют интересы правосудия, также является неотъемлемой частью справедливости судебного разбирательства.

Являясь неотъемлемой частью комплексного права, предусмотренного в статье 6 Конвенции, и проявляясь в разных аспектах, степень и качество обеспечения права на участие в деле адвоката имеет непосредственное влияние на всю справедливость судебного разбирательства. Хотя в прецедентной практике Европейского Суда участие адвоката в судебном разбирательстве не рассматривается в качестве абсолютного права, но оценивается как дополнительная гарантия соблюдения процессуальных норм.

Вопросы участия адвоката в уголовном процессе в контексте права на справедливое судебное разбирательство рассмотрены автором через анализ и систематизацию прецедентной практики Европейского Суда по правам человека.

Ключевые слова: уголовный процесс; адвокат; справедливость судебного разбирательства; минимальные права; прецедентная практика; анализ.

Как отмечается в литературе, система защиты от уголовного преследования состоит из следующих взаимосвязанных элементов:

а) основные принципы и условия уголовного судопроизводства;

б) участие защитника;

в) личная защита;

г) обеспечение прав [3, с. 95].

Подпункт "c" пункта 3 статьи 6 Европейской Конвенции о защите прав человека и основных свобод гарантирует каждому обвиняемому право защищать себя лично или посредством выбранного им самим защитника либо при недостатке у него средств для оплаты услуг защитника, пользоваться услугами назначенного ему защитника бесплатно, когда того требуют интересы правосудия.

\footnotetext{
- Халилов Фардин Яшар оглы - доктор философии права, главный научный сотрудник Академии Юстиции Министерства Юстиции Азербайджанской Республики. E-mail: ph_d@mail.ru
} 
Хотя в интерпретации Европейского Суда подпункт " $c$ " пункта 3 статьи 6 в некой мере совпадает с подпунктом " $b$ " того же пункта той же статьи [16], первый все же является более широким, так как он не связывает услуги адвоката только с подготовкой защиты к судебной стадии производства, а гарантирует адвокатскую помощь и поддержку на всем протяжении производства [9].

Право обвиняемого защищаться от уголовного преследования лично, то есть без помощи адвоката-защитника гарантируется Конвенцией [15], но государство не вправе требовать от уголовно преследуемого лица защищаться лично, то есть без помощи адвоката [29]. В случае отказа от адвоката для дальнейшего осуществления защиты лично самим обвиняемым, такой отказ должен быть установлен недвусмысленно и сопровождаться минимальными гарантиями, соразмерными важности отказа от адвоката [34], быть добровольным, осмысленным и осознанным [40].

Вместе с тем, право уголовно преследуемого лица защищаться лично не является абсолютным правом [10]. Это означает, что установление внутригосударственным уголовнопроцессуальным законодательством обстоятельств, требующих обязательного участия в уголовном судопроизводстве адвоката-защитника, либо круга отдельных категорий производств, где представление интересов обвиняемого допускается только через участие в деле адвоката, не противоречит Конвенции, если критерием установления данных положений выступает «интересы правосудия» [27].

В свою очередь, Европейский Суд не определяет круг обстоятельств обязательного участия адвоката-защитника, соответствующих интересам правосудия, считая, что в данном вопросе внутригосударственные органы находятся в лучшем, чем Европейский Суд положении для оценки обстоятельств, где защита обвиняемого через адвоката является более уместным для интересов правосудия. Тем самым, Европейский Суд допускает обязательное предоставление адвокатской помощи обвиняемому по усмотрению внутригосударственных органов [11].

Право на защиту через посредство приглашенного обвиняемым адвоката [12], в том числе назначенного государством, также как и в случае с правом обвиняемого защищаться лично, не является абсолютным [41]. Но ввиду важности этого права для справедливости судебного разбирательства, уголовно преследуемое лицо должно быть своевременно, и не позднее первого допроса уведомлено о своем праве получать помощь адвоката [30], само право на защиту через посредство адвоката также должно быть обеспечено не позднее первого допроса подозреваемого правоохранительными органами [28]. Исключением из данного правила могут являться допросы, проведенные органами полиции, в связи проведением проверки на дорогах до задержания лица [4]. Следует также учесть, что хотя статья 6 требует, чтобы обвиняемому была предоставлена правовая помощь защитника уже на начальной стадии допросов, проводимых правоохранительными органами, это право, которое прямо не установлено Конвенцией, может быть ограничено при наличии достаточных оснований. В любом случае, встает вопрос, лишают ли эти ограничения в свете всего объема процессуальных действий обвиняемого его права на справедливое судебное разбирательство? [19].

Если обвиняемый был лишен возможности воспользоваться услугами адвоката, и был допрошен в отсутствие защитника на досудебном производстве, но полученные данным способом инкриминирующие показания не были использованы в суде, и не легли на основу обвинительного приговора, Конвенция считается не нарушенной [42], в то время как, исполь- 
зование изобличающих показаний обвиняемого, данных на досудебном производстве в отсутствие его адвоката при вынесении обвинительного приговора оценивается Европейским Судом в качестве нарушения Конвенции [38].

В литературе, ссылаясь на постановление Европейского Суда по делу Imbrioscia v. Switzerland [18], отмечается, что подпункт "c" пункта 3 статьи 6 не требует от государства по своей инициативе предлагать адвокату обвиняемого присутствовать на допросах в ходе следствия. Однако, хотя Европейский Суд не заявил об этом столь развернуто, основной посыл данного постановления, по-видимому, заключается в том, что когда сам адвокат или обвиняемый требует присутствие адвоката, это требование должно быть удовлетворено, если полученная информация может причинить ущерб защите обвиняемого, и по всей вероятности, данная опасность существует [2, с. 641].

Тем не менее, право на услуги адвоката само по себе не связано с первым допросом уголовно преследуемого лица, так как у последнего должна быть возможность пользоваться услугами адвоката в самом начале лишения его свободы в виде задержания, либо заключения под стражу [14].

Право на защиту через посредство адвоката подразумевает не формальную, а практическую и эффективную правовую помощь. Назначение обвиняемому адвоката, само по себе, не является достаточной мерой для обеспечения права на защиту через посредство адвоката [6], если назначенный адвокат не предпринимает каких-либо действий в интересах своего подзащитного, либо предпринимаемые им действия очевидно неэффективны для защиты. Несмотря на то, что государство несет ответственность за обеспечение данного права, оно не несет ответственность за качество деятельности адвоката, осуществляющего защиту обвиняемого, даже если он был назначен государством (за исключением случаев, когда адвокат является публичным защитником, который состоит на службе у государства) [5].

В контексте вопроса взаимосвязи гарантий эффективности адвокатской помощи, и обязанностей государства, к последним можно отнести обязанность воздержания от частых замен адвокатов [23], обязанность уведомления адвоката о предстоящем судебном заседании [16], обязанность предоставления адвокату возможности для выступления [7] и т.д.

По общему правилу, осуществление защиты является, главным образом, вопросом отношений между обвиняемым и его защитником. Вместе с тем, государство имеет обязанность вмешательства в дело, если услуги, оказываемые адвокатом, назначенным государством, явно неэффективны, либо такая неэффективность была в достаточной мере донесена до внимания государственных органов [20]. За государством, также может быть признана обязанность вмешательства в дело в интересах правосудия, в случаях оказания правовой помощи приглашенным обвиняемым защитником по некоторым категориям дел (например, если уголовно преследуемое лицо является несовершеннолетним, и инкриминируемое ему преступление является тяжким и т.п.), при явной небрежности приглашенного обвиняемым адвоката [17].

В прецедентной практике Европейского Суда прослеживается тенденция разграничения явной небрежности [17], либо ошибки адвоката процессуально-правового характера [13] от иных профессиональных ошибок [39] адвокатов в линии защиты, в аргументации и т.п. Так называемые «иные» профессиональные ошибки адвокатов, как правило, не требуют вмешательства государства, даже если правовая помощь обвиняемому оказывается адвокатом, назначенным государством. 
Суд, также оценивает эффективность оказываемой юридической помощи в тесной взаимосвязи с правом на конфиденциальное общение с адвокатом. Для обеспечения данного права обвиняемый должен иметь возможность встречаться со своим адвокатом наедине, как на досудебных, так и на судебных стадиях разбирательства его дела, в условиях исключающих подслушивания их беседы государственными органами, ведущими производство по делу, либо работниками мест лишения свободы. В свою очередь, количество и продолжительность встреч защитника со своим подзащитным являются критериями эффективности реализации права на помощь адвоката [28].

Следует иметь в виду, что гарантии конфиденциального общения обвиняемого со своим адвокатом распространяются и на корреспонденцию [26] и на телефонные разговоры [43] между ними. Ограничение конфиденциальности корреспонденции между обвиняемым и его адвокатом, также рассматриваются Европейским Судом в контексте статьи 8 (право на уважение частной и семейной жизни) Конвенции [8]. Кроме того, конфиденциальность оказываемой юридической услуги адвокатом гарантируется своеобразным иммунитетом рабочего места последнего от обысков [22].

Только при наличии «очень серьезных оснований» [21] Суд может посчитать вмешательство со стороны государства в контакты обвиняемого, содержащегося под стражей и его адвоката, приемлемым [10].

«Очень серьезные основания» должны быть обусловлены опасениями того, что адвокат злоупотребляет своим профессиональным положением, действуя в сговоре с подзащитным по сокрытию или уничтожению доказательств или иными способами (например, путем использования свиданий со своим подзащитным с целью воздействовать угрозами на свидетеля), серьезно препятствуя осуществлению правосудия. В свою очередь, к допустимым, в контексте права на справедливое судебное разбирательство, вмешательствам государства в контакты защитника и его подзащитного, содержащегося под стражей, в доктрине относят проведение свиданий между защитником и подзащитным в условиях, исключающих (ограничивающих) конфиденциальность, и временный запрет самих свиданий, не занимающий значительную часть предварительного расследования [1, с. 105-109].

Европейский Суд не связывает право на помощь адвоката с присутствием обвиняемого [35], и констатирует нарушение Конвенции, в случаях осуществления производства без участия адвоката в связи с отсутствием обвиняемого даже тогда, когда обвиняемый скрывается от правосудия, либо неявкой нарушает взятое на себя обязательство. Даже в случаях, когда обвинительный приговор, вынесенный in absentia, может быть отменен в ходе последующего рассмотрения дела, производства, осуществленные без участия адвоката, стали причинами констатации нарушения Конвенции [33].

Европейский Суд обуславливает реализацию права на бесплатную помощь адвоката двумя факторами: недостаточность материальных средств обвиняемого для оплаты услуг адвоката [29], и необходимость такой помощи с точки зрения обеспечения интересов правосудия [32].

Вместе с тем, он не определил в своей прецедентной практике конкретные критерии, либо минимальные объемы средств обвиняемого, которые могли бы приниматься во внимание при оценке недостаточности его средств, что позволяет сделать вывод о «не строгом» подходе Европейского Суда к данному вопросу. Так, например, по делу Correiade Matos v. Portugal, Европейский Суд признал за государствами право на «поле усмотрения» при реше- 
нии вопроса о предоставлении адвокатской помощи за счет государства [11]. Можно, также сделать вывод о том, что обязанность доказывания недостаточности своих средств лежит на обвиняемом [29].

Относительно второго фактора, обуславливающего предоставление бесплатной адвокатской помощи, Европейским Судом были констатированы такие критерии как сложность дела, заключающаяся в лишении возможности обвиняемого аргументировать свою позицию ввиду сложности правовых вопросов, затронутых в деле, либо возможность в силу тех же причин осуществления эффективной защиты по делу только профессиональным адвокатом [32], сложность подлежащей к применению по делу законодательства [31], тяжесть ожидаемой обвиняемого санкции [36], отсутствие у обвиняемого возможности следить за ходом рассмотрения дела [37]. Вместе с тем, следует учесть, что при получении адвокатской помощи за счет государства, обвиняемый не вправе выбирать себе адвоката, либо высказать свое мнение на счет назначенного ему адвоката [25], хотя, согласно правовой позиции Европейского Суда, желание обвиняемого может быть учтено в таких случаях. Но, тем не менее, право на выбор адвоката, предоставляющего правовую помощь за счет государства, всегда остается за государственными органами [24].

Подытоживая вышесказанное, можно сделать вывод, что являясь неотъемлемой частью комплексного права, предусмотренного в статье 6 Конвенции, и проявляясь в разных аспектах, степень и качество обеспечения права на участие в деле адвоката имеет непосредственное влияние на всю справедливость судебного разбирательства. Хотя в прецедентной практике Европейского Суда участие адвоката в судебном разбирательстве не рассматривается в качестве абсолютного права, но оценивается как дополнительная гарантия соблюдения процессуальных норм.

В контексте права на справедливое судебное разбирательство адвокатская помощь в уголовном процессе должна осуществляться на равных правовых условиях со стороной обвинения относительно доступа к материалам дела и процессуальных возможностей аргументации своей позиции; быть обеспеченным достаточным временем и конфиденциальностью; быть оказанным своевременно; иметь практический характер и необходимый объем для эффективности защиты; в случаях, обусловленных интересами правосудия предоставляться за счет государства, и вне зависимости от волеизъявления обвиняемого.

\section{Библиография}

1. Брусницын Л.В. Ограничение права на свидания защитника с подзащитным в национальном и международном праве // Государство и право. - 2002. - №11. - С. 105-109.

2. Право Европейской конвенции по правам человека / Харрис, О’Бойл, Уорбик. [пер. с англ. Власихин В.А. и др.]. - М.: Развитие правовых систем, 2016. - 1432 с.

3. Сулейманов Д.И., Исмайлова С.Р., Раджабова Т.Ф., Теймуров А.А. Права человека и уголовный процесс. Руководство по справедливому судопроизводству. - Баку: Сада, 2019. $417 \mathrm{c}$.

4. Aleksandr Zaichenko v. Russia, 28.06.2010, (Application no. 39660/02).

5. Alvarez Sanchez v. Spain, 23.10.2001, (Application no. 50720/99).

6. Artico v. Italy, 13.05.1980, 3 E.H.R.R. 1. 
7. Biondo v. Italy, 05.05.1983, (Application no. 8821/79).

8. Campbell and Fell v. United Kingdom, 28.06.1984, 7 E.H.R.R. 165.

9. Can v. Austria, 30.09.1985, (Application no. 9300/81).

10.Castravet v. Moldova, 13.06.2007, (Application no. 23393/05).

11.Correia de Matos v. Portugal, 15.11.2001, (Application no. 48188/99).

12.Croissant v. Germany, 25.09.1992, 16 E.H.H.R. 135.

13.Czekalla v. Portugal, 10.10.2002, (Application no. 38830/97).

14.Dayanan v. Turkey, 13.01.2010, (Application no. 7377/03).

15.Foucher v. France, 18.03.1997, (Application no. 22209/93).

16. Goddi v. Italy, 09.04.1984, 6 E.H.R.R. 457.

17. Güveç v. Turkey, 20.01.2009, (Application no. 70337/01).

18. Imbrioscia v. Switzerland, 24.10.1993, 17 E.H.R.R. 441.

19. John Murray v. United Kingdom, 08.02.1996, 22 E.H.R.R. 29.

20. Kamasinski v. Austria, 19.12.1989, 19 E.H.R.R. 36.

21. Kempers v. Austria, 27.02.1997, (Application no. 21842/93).

22. Khodorkovskiy and Lebedev v. Russia, 25.10.2013, (Application nos. 11082/06 and 13772/05).

23. Köplinger v. Austria, 29.03.1966, (Application no. 1850/63).

24. Lagerblom v. Sweden, 14.01.2003, (Application no. 26891/95).

25. M v. United Kingdom, (1984) 36 D.R. 155.

26. McComb v. United Kingdom, (1968), 50 DR 81.

27. Meftah and Others v. France, 26.07.2002, (Application no. 32911/96).

28. Ocalan v. Turkey, 12.05.2005, 41 E.H.R.R. 985.

29. Pakelli v. Germany, 25.04.1983 (Application no. 8398/78).

30. Panovits v. Cyprus, 11.12.2008, (Application no. 4268/04).

31. Perks and others v. United Kingdom, 12.10 .1999 (Application nos. 25277/94, 25279/94, 25280/94, 25282/94, 25285/94, 28048/95, 28192/95, 28456/95).

32. Pham Hoang v. France, 29.08.1992, 16 E.H.R.R. 53.

33. Pietilainen v. Finland, 22.09.2009, (Application no. 13566/06).

34. Pishchalnikov v. Russia, 24.12.2009, (Application no. 7025/04).

35. Poitrimol v. France, 23.11.1993, 18 E.H.R.R. 130.

36. Quaranta v. Switzerland, 24.05. 1991, (Application no. 12744/87).

37. Timergaliyev v. Russia, 14.10.2008, (Application no. 40631/02).

38. Salduz v. Turkey, 27.11.2008, (Application no. 36391/02).

39. Stanford v. United Kingdom, 23.02.1994, (Application no. 16757/90).

40. Şaman v. Turkey, 05.07.2011, (Application no. 35292/05).

41. Yaremenko v. Ukraine, 12.09.2008, (Application no. 32092/02).

42. Yurttas v. Turkey, 27.05.2004, (Application nos. 25143/94 and 27098/95).

43. Zagaria v. Italy, 27.11.2007, (Application no. 58295/00). 